\title{
Relationship of knowledge to learn in programming methodology and evaluation of computational thinking
}

\author{
Arturo Rojas López \\ Division of TIC \\ Antiguo camino a la resurrección 1002-A Universidad Tecnológica de Puebla
}

(+52) 2223088861

arturo.rojas@utpuebla.edu.mx

\author{
Francisco J. García-Peñalvo \\ GRIAL Research Group,
}

Research Institute for Educational Sciences,

University of Salamanca

Paseo de Canalejas 169, 37008

Salamanca, Spain

(+34) 923294500 ext. 6095

fgarcia@usal.es

\begin{abstract}
Computational thinking (CT) is a way that allows us to create solutions to problems through the use of skills such as abstraction, decomposition, generalization, evaluation and algorithmic design. There are Institutions that offer global CT assessment to particularly promote the study of professions in the area of Computer Science and in some cases there is also training for teachers of primary and secondary education. In this paper we present the proposal to evaluate the CT skills of new students in the Division of Technologies Information and Communication of the Universidad Tecnológica de Puebla to relate the knowledge indicated in the Programming Methodology course and provide an initial environment that accredits learning, review or learn as determined by the test in order to motivate the student who already has a knowledge and attends the required education. The main conclusion of the work is to create learning scenarios through assessing the skills mentioned initially using reagents internationally recognized.
\end{abstract}

\section{CCS Concepts}

- Social and professional topics $\rightarrow$ Computing education $\rightarrow$ Computational thinking.

\section{Keywords}

Computational Thinking; Computer Programming Course; Curriculum Design; Educational Programming; Engineering Course; Engineering Education; Engineering Problems; Eirst Year Students; Higher Education; Introductory Programming Course; Learning Programming; Programming; Programming Teaching; Students; Teaching; Work in Progress.

\section{INTRODUCTION}

CT application in higher education is directed towards the disciplines of Science, Technology, Engineering and Mathematics as expounded Swaid [1]; to Román et al. [2] represents the "focus of educational innovation by all problem solving skills to be acquired by new generations of students."

Skills can be learned through a game model and in turn introduce programming concepts to avoid being a "frustrating and demanding activity by students" [3] without forgetting that the CT is not a synonym for programming.

Works that relate the CT with the initial study computer programming as Lorkins and Harvey [4] consider not only students in the area of Computer Science (CS) but those who come from a variety of science and engineering to solve problems in their areas, including doctoral level [5]; for the specific case of CS we have to go beyond "train students to solve problems using a programming language into practice" [6], we have to find motivation to them, because "it is an important factor to improve student performance" [7].

In the last thirteen years, the usual way of imparting the initial programming course has been one hundred percent in person, seeking to unify learning for all students through theoretical and practical manuals of the subject, departmental examinations, academies by a different full-time teacher each quarter and completely based as indicated in the sheet of course designed nationally by the Coordinación General de las Universidades Tecnológicas at the time. In Puebla factors such as desertion, high and variable rate of failure, lack of academic performance of students outside the facilities, make it necessary to propose other ways that benefit the quality of education. In this scenario, we propose to redesign the teaching practice through the use of CT that has an impact on learning programming. Our work presents the 
novelty of avoiding unique content for all students in the Programming Methodology (PM) course. In the context section, we present the framework of concepts that help justify the proposal, mainly the relationship of computational thinking and content of the initial programming course. In the description section, the questions selected to evaluate the skills of abstraction, decomposition, generalization, evaluation and algorithmic design are presented. The results are important in providing learning scenarios for students as well as an evaluation experiment conducted with students from third quarter. Finally the conclusion of the work done and the importance of future work are exposed.

\section{CONTEXT}

The work seeks to redesign the PM course, which is included in the first quarter of the career Técnico Superior Universitario of Division Information Technology and Communication (ITC) at the Universidad Tecnológica de Puebla (UTP); every September starts a new generation and from the Department of Student Services are forming groups for morning and afternoon shift on average are twelve of about thirty students each. The direction of the division ITC determines teachers who taught the subject based on availability reported by the course teachers or full time. The aim of the course, in each thematic unit, as well as the description of Knowledge and Know to Do of each topic is written based on a cognitive category Bloom's Taxonomy.

In the initial definition of Computational Thinking Wing [8] proposes that this involves solving problems, designing systems and understanding human behavior, based on fundamental concepts for CS making it useful in an initial course of programming. With the passage of time solving problems continued being part of the definition as those offered by Barr [9] and Garcia [10] as well as the relationship with the CS in the definition of the Royal Society [11]. Interest in teaching the Computational Thinking at an early age is presented through the document Standards in Computer Science [12] at North America, project and website TACCLE3 from Europe [13] with work in progress [14-16] and Computing our future [17], and its impact is important that James and George [18] considers a root element for the success of the student in Computer Science. The Selby's study [19] explores the relationship between the CT, teach programming and Bloom's taxonomy; initially developed a definition of CT skills including generalization, decomposition, abstraction, algorithmic design and evaluation; subsequently mapped to the cognitive domain of Bloom's taxonomy to concentrate as follows: at the Application level skill generalization, Analysis skills of abstraction and decomposition, Synthesis ability of algorithmic design and Evaluation corresponds to the ability evaluation; finally it relates programming knowledge that correspond teach.

The definition of the relationship that we propose between knowledge of the course PM and the CT is as follows:

- The thematic unit One: "basics" in the concept Knowledge indicates in his six verbs issues of level two of Bloom's taxonomy (Identify, recognize and describe), in the concept Know to Do a verb at the same level and other in fourth (Sketch) so they are in the Know level and Analyze level therefore correspond to the skills of Abstraction and Decomposition.

- The thematic unit Two: "expressions" used in the three subjects the verb Identify in concept Knowledge that corresponds to level two of Bloom, while in the concept Know to Do uses twice verbs of level three Apply corresponding to the Generalization ability.

- The thematic unit Three: "algorithms and flowcharts" has four themes, the concept Knowledge displayed verbs of cognitive level two Understanding and the concept Know to Do a verb level five Evaluate, besides indicating programming exercises using the paradigm structured programming, so corresponds to the skills Evaluation and Algorithmic design.

Therefore, using the mentioned relationship and the manner in which are determined the contents of the subject, the reagents are chosen to evaluate the CT of new students and provide an initial learning environment where motivated to study the subject with based on the identified skills.

\section{DESCRIPTION}

The reagents were chosen from two recognized sources at International level: the contest "about informatics and computational fluency school age" [20] UK Bebras and Computer Olympiad Talent Search [21] "that aims to guide South African students with more skills in CT towards technical careers" [2]; because its original form is in English, a Spanish translation is done. The Bebras exercise called Mobile assesses greatly the ability of decomposition, the ratio of the image with the expression of numbers and parentheses leads to determine that the mobile is a small mobile composition see Figure 1.

The exercise named Kangaroo, also Bebras, noted for its assessment of abstraction as the student chooses, analyzes and determines what information is attending to get the correct answer of the problem, see Figure 2. The third exercise taken from Bebras named Spies focuses on evaluating the ability of generalization; because once that verifies the right solution for the initial problem; applied to a similar situation to solve the problem that has similar characteristics, see Figure 3. Two reagents are taken from the Computer Olympiad, the first named Beavers on the Run is chosen to evaluate the ability of algorithmic design because the student to resolve it shows your ability to understand the organization of instructions for solving a problem, in this case the indications for beavers cross holes, see Figure 4. 
Rojas López, A., \& García-Peñalvo, F. J. (2016). Relationship of knowledge to learn in programming methodology and evaluation of computational thinking. In F. J. García-Peñalvo (Ed.), Proceedings of the Fourth International Conference on Technological Ecosystems for Enhancing Multiculturality (TEEM'16) (Salamanca, Spain, November 2-4, 2016) (pp. 73-77). New York, NY, USA:

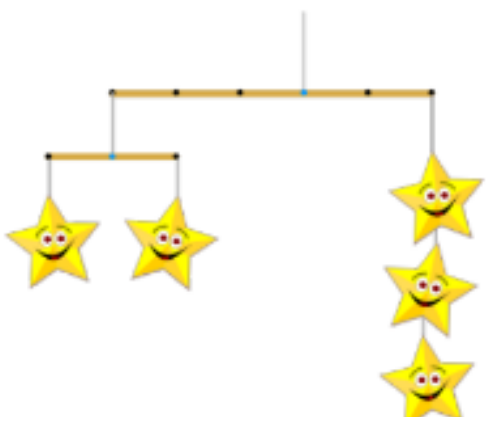

Figure 1. Description of Mobile with an expression:

$$
\left.\left(\begin{array}{lll}
-3 & (-1 & 1
\end{array}\right)\left(\begin{array}{ll}
1 & 1
\end{array}\right)\right)\left(\begin{array}{ll}
2 & 3
\end{array}\right)
$$

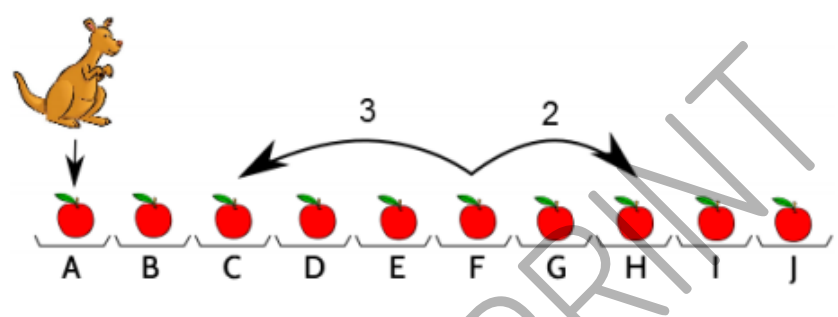

Figure 2. The task of picking apples

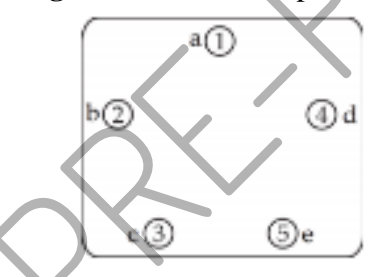

Figure 3. Five spies exchanging information

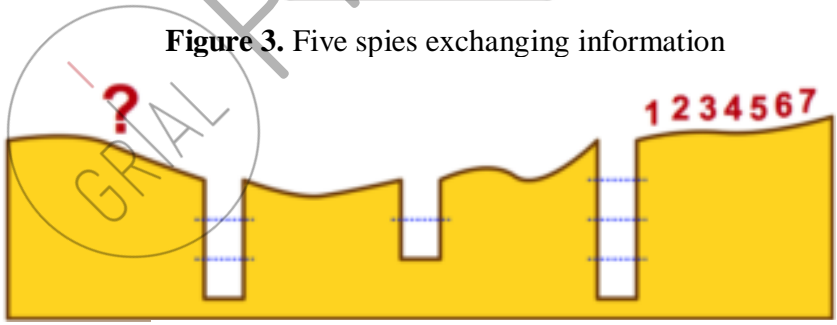

Figure 4. Seven beavers looking cross hole

The second reagent named Puddle Jumping is chosen to determine the ability of evaluation, perform step by step instructions to complete the exercise and obtain the requested response, see Figure 5.

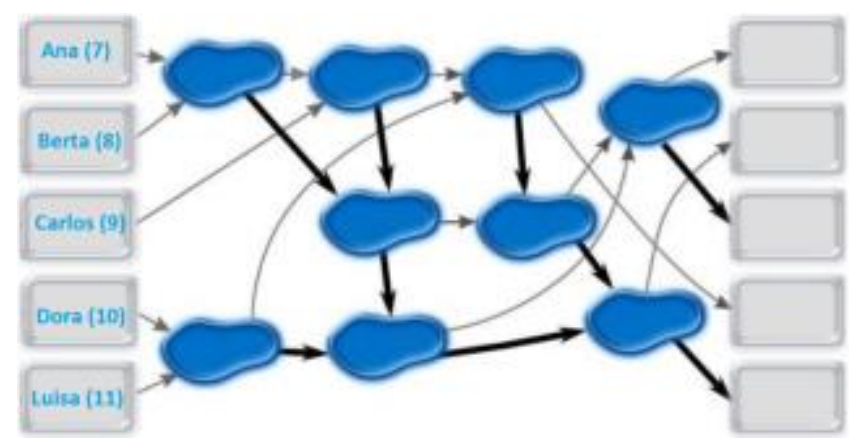

Figure 5. Puddle Jumping 


\section{RESULTS}

The activities proposed to offer the student an initial learning environment based on reagents answered correctly, they are identified in 8 stages:

\section{Scenario 1.5 right answers}

The student has right to online material course and he can perform fifteen days after of start the quarter the evaluation of the thematic units through tests developed using the Moodle platform and deliver practical exercises created by the academy, if approving the results, the student accredits the course, otherwise a date for the review in person teacher-student exercises is determined, doubts are clarified and the student can choose, new practical exercises to evaluate or take the online course.

\section{Scenario 2. Wrong exercise Beavers on the Run}

The student must reinforce the algorithmic design with exercises through the Moodle platform, perform full course evaluations one month after the quarter started and determine whether he accredits the subject or choose to take it online.

\section{Scenario 3. Wrong exercise Puddle Jumping}

Strengthen sequential, decision and repetition structures, coding specific exercises that solve a problem using the control structures. Scheduling attendance counseling for these issues and laboratory practice, make full course evaluations a month after the quarter started and determine whether to approve the subject or choose to take it online.

\section{Scenario 4. Wrong exercises Beavers on the Run and Puddle Jumping}

The student has right to use the online material course and he can practice activities to programs exercises of structured programming proposed by the academy, he can schedule three sessions of counseling with the teacher and he may ask the evaluation of online surveys and practical exercises a month started the quarter. If accredits their assessments, also the course, otherwise he can choose to take the course online or blended.

\section{Scenario 5. Wrong exercise Spies}

Strengthen evaluation of arithmetic, logical and relational expressions considering the hierarchy of operators through coding exercises using calculations and conditional operations; make a month after the quarter started full course evaluations and determine whether he accredits or choose to take it online.

Scenario 6. Wrong exercises Beavers on the Run, Puddle Jumping and Spies

The student can work a blended model, where the course material and activities will be released based on the specified time on the road course, requesting counseling sessions with the teacher of the course, make the practices and examinations at times marked by the academy.

\section{Scenario 7. Right exercise Kangaroo or Mobile}

The student has basic skills, but particularly necessary for learning programming, so he can choose for a blended environment, but with an attention in person counseling regular in laboratory practices; perform departmental evaluations indicated by the academy and the student will perform practical exercises to develop the skills they need reinforcement, Generalization and Algorithmic design.

Scenario 8. Wrong on all reagents

There is a possibility that student does not have skills to study the Career and the thematic unit three will be difficult to understand (control structures and algorithmic design), so it is recommended in student-teacher-principal meeting to assess the vocational profile. It is very sure that the classroom course is the best option for the student.

An experiment was conducted with 18 volunteer students third-quarter under the following conditions. He was asked to answer an online survey about knowledge with those who feel already familiar from his first course, Table 1 contains the elements that marked the student, and later performed the evaluation of computational thinking. The intention is to verify the correspondence between their knowledge and skills CT; results determination 6 cases. 
Rojas López, A., \& García-Peñalvo, F. J. (2016). Relationship of knowledge to learn in programming methodology and evaluation of computational thinking. In F. J. García-Peñalvo (Ed.), Proceedings of the Fourth International Conference on Technological Ecosystems for Enhancing Multiculturality (TEEM'16) (Salamanca, Spain, November 2-4, 2016) (pp. 73-77). New York, NY, USA:

ACM.

Case 1. Students who claim to know all the knowledge and correct answers CT reagents by thematic unit, Table 2 represents an ideal outcome relationship.

Case 2. Contradictory results of students who say they know all the knowledge, but got incorrect responses CT reagents by thematic unit, Table 3 shows a number of unwanted values.

Case 3. Difference between students who say they know some of the knowledge and correct answers CT reagents by thematic unit, Table 4 with a high value on three thematic unit illustrates that these students may have a lack of confidence in their knowledge despite being able to resolve the respective exercises.

Case 4. Correspondence between some knowledge indicated as unfamiliar by thematic unity and wrong reactive for the case of two CT skills, the relationship is correct and also justifies the content regularization offer, see Table 5 .

Case 5. Number of students who answered be familiar with all the knowledge of each respective thematic unit and obtained a wrong reactive for the case of two CT skills, number 4 of Table 6 shows that not everything depends on the assessment CT, justifies itself as a guide for teachers as well as evaluation of the contents by generating evidence that determines the academic.

Case 6. Result of which are not yet completely sure of all knowledge by thematic unit and erroneous CT reagents, Table 7 indicates the value 6 of the thematic unit 2, the case of students not respond well to the reactive indicates that do not yet have the relevant skills knowledge of the unit referred.

Table 1. General knowledge by thematic unit

\begin{tabular}{|c|l|}
\hline $\begin{array}{c}\text { Thematic } \\
\text { unit }\end{array}$ & \multicolumn{1}{|c|}{ Knowledge } \\
\hline 1 & $\begin{array}{l}\text { Type of data } \\
\text { Variable identifiers }\end{array}$ \\
\hline 2 & $\begin{array}{l}\text { Arithmetic operators } \\
\text { Logical operators } \\
\text { Relational operators } \\
\text { Hierarchy of operators } \\
\text { Solve expressions }\end{array}$ \\
\hline 3 & $\begin{array}{l}\text { Using counter and accumulator variable } \\
\text { Selection structure (conditional) } \\
\text { Structure repetition (cycle) } \\
\text { Flowchart } \\
\text { Design of Algorithms }\end{array}$ \\
\hline
\end{tabular}

The number of scenarios proposed in section Results set may well correspond to the cases detected in the experiment with students in the third quarter, therefore, how to offer the contents of the course from assessing skills CT represents a novelty for our case study and can serve other similar contexts globally.

\section{CONCLUTIONS}

We have a justified proposal to use the evaluation of Computational Thinking and determine how to study the course of programming methodology for new students. The reagents are guaranteed by their use internationally and their choice based on the ability to evaluate. The relationship between skills evaluated and topics of the subject use the results reported by the work of Selby [5] and based on teaching experience options of learning environment are determined. During the four months from September to December 2016 we can measure the results of the proposed work. It is expected at least to carry it out with two experimental groups assigned by the management of the Division of ITC in UTP, and compare the number of accredited students, desertions and academic level exit, and the learning environment in Moode platform; which generally represents the future work.

Table 2. Ideal Correspondence 


\begin{tabular}{|c|c|}
\hline Thematic unit & Quantity \\
\hline 1 & 6 \\
\hline 2 & 4 \\
\hline 3 & 2 \\
\hline
\end{tabular}

Table 3. Correspondence unwanted

\begin{tabular}{|c|c|}
\hline Thematic unit & Quantity \\
\hline 1 & 2 \\
\hline 2 & 8 \\
\hline 3 & 0 \\
\hline
\end{tabular}

Table 4. Correspondence of Case 3

\begin{tabular}{|c|c|}
\hline Thematic unit & Quantity \\
\hline 1 & 2 \\
\hline 2 & 0 \\
\hline 3 & 13 \\
\hline
\end{tabular}

Table 5. Correct Relationship

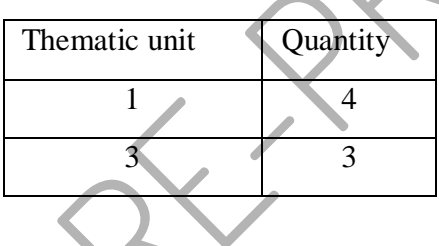

Table 6. Students with a wrong reagent for two skills

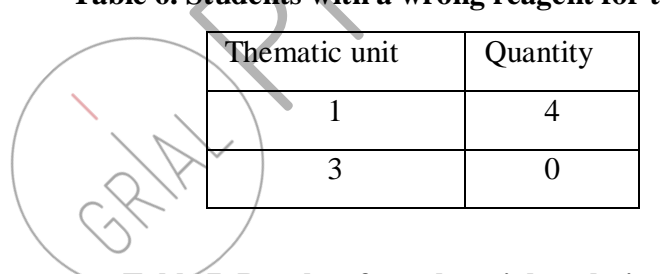

Table 7. Results of another right relationship

\begin{tabular}{|c|c|}
\hline Thematic unit & Quantity \\
\hline 1 & 0 \\
\hline 2 & 6 \\
\hline 3 & 0 \\
\hline
\end{tabular}

\section{Acknowledgements}

This research work is made within University of Salamanca PhD Programme on Education in the Knowledge Society scope.

\section{REFERENCES}

[1] Swaid, S.I. 2015. 6th International Conference on Applied Human Factors and Ergonomics AHFE and the Affiliated Conferences, AHFE 2015 Bringing Computational Thinking to STEM Education, Procedia Manufacturing, Volume 3, 2015, Pages 3657-3662, ISSN 2351-9789, DOI= http://dx.doi.org/10.1016/j.promfg.2015.07.761.

[2] Román M., Pérez J. C., and Jiménez C. 2015. Test de Pensamiento Computacional: diseño y psicometría general Computational Thinking Test: design \& general psychometry, III Congreso Internacional sobre Aprendizaje, Innovación y Competitividad (CINAIC 2015), Octubre 14-16, 2015, Madrid, ESPAÑA 
Rojas López, A., \& García-Peñalvo, F. J. (2016). Relationship of knowledge to learn in programming methodology and evaluation of computational thinking. In F. J. García-Peñalvo (Ed.), Proceedings of the Fourth International Conference on Technological Ecosystems for Enhancing Multiculturality (TEEM'16) (Salamanca, Spain, November 2-4, 2016) (pp. 73-77). New York, NY, USA:

ACM.

[3] Kazimoglu, C., Kiernan, M., Bacon, L., and MacKinnon, L. 2012. Proceedings of the International Conference on Computational Science, Learning Programming at the Computational Thinking Level via Digital Game-Play, Procedia Computer Science, Volume 9, 2012, Pages 522-531, ISSN 1877-0509, DOI= http://dx.doi.org/10.1016/j.procs.2012.04.056.

[4] Larkins, D.B. and Harvey, W. ICCS 2010 Introductory computational science using MATLAB and image processing, Procedia Computer Science, Volume 1, Issue 1, 2010, Pages 913-919, ISSN 1877-0509, DOI= http://dx.doi.org/10.1016/j.procs.2010.04.100.

[5] Shiflet, G.W., and Shifleta, A.B. Proceedings of the International Conference on Computational Science, ICCS 2012. Introducing Life Science Doctoral Students in $\mathrm{Oz}$ to the Wizardry of Computational Modeling: Introducing Computational Thinking with CellDesigner $^{\mathrm{TM}}$, Procedia Computer Science, Volume 9, 2012, Pages 1753-1762, ISSN 1877-0509, DOI= http://dx.doi.org/10.1016/j.procs.2012.04.193.

[6] Lingling, Z., Su, X., and Wang, T. International Educational Technology Conference, IETC 2014, 3-5 September 2014, Chicago, IL, USA Bring CS2013 Recommendations into c Programming Course, Procedia - Social and Behavioral Sciences, Volume 176, 2015, Pages 194-199, ISSN 1877-0428, DOI= http://dx.doi.org/10.1016/j.sbspro.2015.01.461

[7] A. Ramirez, A., Muñoz, D.F. International Educational Technology Conference, IETC 2014, 3-5 September 2014, Chicago, IL, USA Increasing Practical Lessons and Inclusion of Applied Examples to Motivate University Students during Programming Courses, Procedia - Social and Behavioral Sciences, Volume 176, 2015, Pages 552-564, ISSN 1877-0428, DOI= http://dx.doi.org/10.1016/j.sbspro.2015.01.510.

[8] Wing, J. M. 2006. Computational Thinking. Communications of the ACM, 49(3), 33-35. DOI= http://10.1145/1118178.1118215

[9] Barr, V., and Stephenson, C. 2011. Bringing computational thinking to K-12: What is Involved and What is the role of the computer science education community? ACM Inroads, 2(1), 48-54. DOI=http://10.1145/1929887.1929905

[10] García-Peñalvo, F. J. 2016. What Computational Thinking Is. Journal of Information Technology Research, 9(3), v-viii.

[11] Royal Society. (2012). Shut down or restart: The way forward for computing in UK schools. Retrieved from London, UK: https://royalsociety.org/ /media/education/computing-in-schools/2012-01-12-computing-in-schools.pdf

[12] CSTA. 2011. K-12 Computer Science Standars. Retrieved from http://csta.acm.org/Curriculum/sub/CurrFiles/CSTA_K-12_CSS.pdf

[13] TACCLE 3 Consortium. 2016. TACCLE 3: Coding Erasmus + Project website. Retrieved from http://www.taccle3.eu/

[14] García-Peñalvo, F. J. 2016. Proyecto TACCLE3 - Coding. In F. J. García-Peñalvo \& J. A. Mendes (Eds.), XVIII Simposio Internacional de Informática Educativa, SIIE 2016 (pp. 187-189). Salamanca, España: Ediciones Universidad de Salamanca.

[15] García-Peñalvo, F. J. 2016. Presentation of the TACCLE3 Coding European Project. Retrieved from http://repositorio.grial.eu/handle/grial/654

[16] García-Peñalvo, F.J., 2016. A brief introduction to TACCLE 3 - Coding European Project. In 2016 International Symposium on Computers in Education (SIIE), F.J. García-Peñalvo and J.A. Mendes Eds. IEEE, USA.

[17] European Schoolnet. 2015. Computing our future - Computer programming and coding, Priorities, school curricula and initiatives across Europe.

[18] James L., and George L. F. 2009. Thinking about/computational thinking, Proceedings of the 40th ACM technical symposium on Computer science education, Chattanooga, TN, USA, pp. 260-264.

[19] Selby, C.C. 2015. Relationships: computational thinking, pedagogy of programming, and Bloom's Taxonomy. In Proceedings of the Workshop in Primary and Secondary Computing Education (WiPSCE '15). ACM, New York, NY, USA, 80-87, DOI= http://dx.doi.org/10.1145/2818314.2818315.

[20] UK Bebras Computational Thinking Challenge, answers 2015, University of Oxford, available http://www.bebras.org

[21] Talent Search. 2015, Elite : Grade 12+, Institute of IT Professionals South Africa, available http://www.olympiad.org.za 